\title{
APPLICATION OF DIGITAL IMAGE CORRELATION TO DETERMINE THE MECHANICAL PROPERTIES OF BIOMATERIALS
}

\author{
B. Gzik-Zroska*, K. Joszko**, W. Wolański ${ }^{* * *}$, E. Kawlewska ${ }^{\dagger}$, M. Burkacki ${ }^{\ddagger}$, S. Suchoń ${ }^{\dagger \dagger}$
}

\begin{abstract}
Identification of mechanical properties of anatomical elements is crucial in the process of creating numerical models. The modelling process relies on the knowledge of modelled elements material properties. Bones are inhomogeneous and anisotropic, but in the numerical simulations the bone material is simplified to the elastic isotropic martial therefore it is necessary to determinate the Young's modulus and Poisson's ratio of bone. There are few main experimental tests to determine Young's modulus, such as static tensile or compressing probe, three or four-point bending. To calculate the Poisson's ratio the extensometer can be used however it should be noticed that this method is burdened with many errors due to the incorrect fixing of the sensor. In this paper authors present new approach to identification of anatomical elements mechanical properties. The described method includes three point bending to determinate the Young's modulus with simultaneous digital image correlation (DIC) to determinate the Poisson's ratio. The obtained results indicate that with the use of DIC technique the Poisson's ratio and also the Young's modulus can be calculated with higher accuracy.
\end{abstract}

Keywords: swine ribs, DIC, three-point bending, Young's modulus, Poisson's ratio

\section{Introduction}

The modelling process rely on the knowledge of modelled elements' material properties. The material properties are influenced by numerous factors, such as genetics, sex, age and nutrition (Agnew et al., 2015, Schafman et al., 2016). Observations conducted on real-life objects (Kokot et al., 2012), tests performed on post-mortem material and numerical analysis constitute the main source of knowledge of biomechanical features of human body elements (Gzik-Zroska et al., 2013, Perz et al., 2015). Many experiments are carried out on human specimens (Kemper et al., 2007, Maltese et al., 2008, Pezowicz et al., 2012) but due to the character of such tests and difficulty in obtaining the material problems researches often use animal's specimens, and obtained results apply to further simulations (Bradley et al., 2014, Kajzer et al., 2013). The main aim of presented work was to calculate the Young's modulus and Poisson's ratio of swine ribs, based on the static 3-point bending probe with simultaneous registration of transversal and longitudinal displacements with the use of digital image correlation system.

Bożena Gzik-Zroska, PhD., Eng.: Department of Biomaterials and Medical Devices Engineering, Faculty of Biomedical Engineering, Silesian University of Technology, Zabrze, PL, bgzikzroska@polsl.pl

** Kamil Joszko, PhD., Eng.: Department of Biomechatronics, Faculty of Biomedical Engineering, Silesian University of Technology, Zabrze, PL, kjoszko@polsl.pl

*** Assoc. Prof. Wojciech Wolański, DSc., Eng.: Department of Biomechatronics, Faculty of Biomedical Engineering, Silesian University of Technology, Zabrze, PL, wwolanski@polsl.pl

$\dagger \quad$ Edyta Kawlewska, PhD. Eng.: Department of Biomechatronics, Faculty of Biomedical Engineering, Silesian University of Technology, Zabrze, PL, ekawlewska@polsl.pl

$\$ \quad$ Michał Burkacki, MSc. Eng.: Department of Biomechatronics, Faculty of Biomedical Engineering, Silesian University of Technology, Zabrze, PL, mburkacki@polsl.pl

\# Sławomir Suchoń, MSc. Eng.: Department of Biomechatronics, Faculty of Biomedical Engineering, Silesian University of Technology, Zabrze, PL, ssuchon@polsl.pl 


\section{Material and methods}

\subsection{Specimens characteristic}

Research material encompassed the bones of swine ribs. In total 87 ribs were tested. They were taken from 29 swine at the age of 6 months in two weight groups: under $90 \mathrm{~kg}(75 \mathrm{~kg}-90 \mathrm{~kg}$ ) and above $90 \mathrm{~kg}$ $(91 \mathrm{~kg}-110 \mathrm{~kg})$. Three ribs were sampled from each swine, from the right and/or left side: fourth, fifth and sixth rib. Prior to mechanical properties testing bones were manually cleared of the adjacent tissues and stored at $4{ }^{\circ} \mathrm{C}$ in a plastic container for $24 \mathrm{~h}$. The length of the sampled rib sections was around $100 \mathrm{~mm}$. Each specimen was measured to calculate the cross-sectional area, which is necessary to determine the Young's modulus.

\subsection{Experimental stand}

All specimens were subjected to a three-point bending test on a strength testing machine MTS Insight 2 with simultaneously used digital image correlation (Fig. 1). MTS Insight 2 is electro-mechanical machine for low-force static tests up to $2 \mathrm{kN}$. Bending force was applied in the direction consistent with the physiological load of the ribs during breathing. Two support points were spaced at a distance of $50 \mathrm{~mm}$. The load was applied to the specimens with a constant velocity of $2 \mathrm{~mm} / \mathrm{min}$ until complete destruction. Additionally, with the use of DIC deflection arrow, in the direction of load, was measured. Before testing each rib was specially prepared. All specimens were covered with a white coating and then with black spots creating a random pattern. The painting did not influence obtained results in any way.

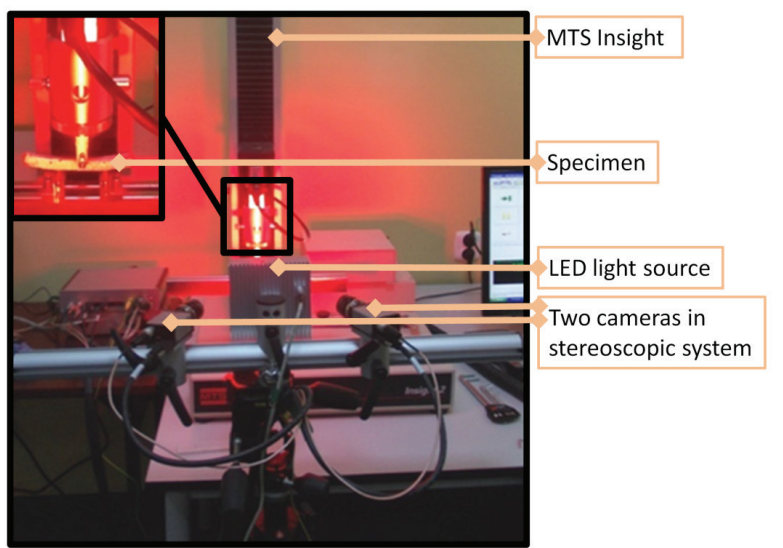

Fig. 1:Testing station: strength testing machine MTS Insight 2 and digital $3 D$ image correlation system (DIC)

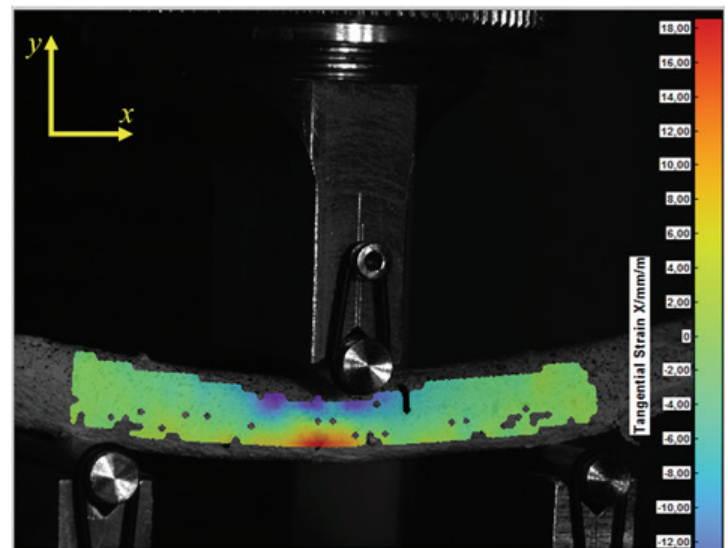

Fig. 2: Rib strain distribution map obtained in DIC

\subsection{Data analysis}

Procedure of data acquisition and data processing was presented in the Fig. 3. During the bending test the values of force $\mathrm{F}(\mathrm{N})$ and displacement $\mathrm{d}(\mathrm{mm})$ in the direction of bending $(\mathrm{y})$ of the specimen were recorded. Also the deflection and strain were recorded by DIC system (Fig. 2).

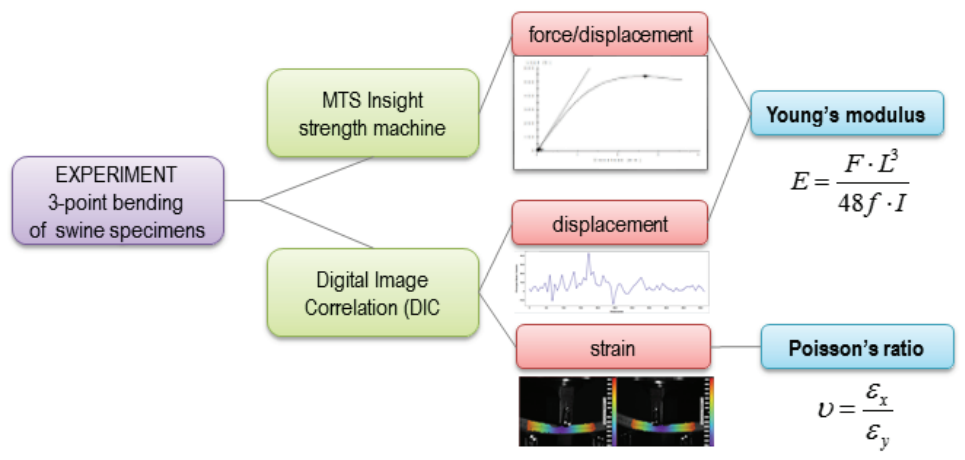

Fig. 3: Procedure of obtaining data in experimental test 
Geometrical values of the ribs (thickness, width) necessary to calculate the Young's modulus were measured with electronic slide calliper with accuracy up to $\pm 0.005 \mathrm{~mm}$. The test results enabled the determination of maximum force and maximum stress which occurred at the moment of the specimen destruction. The Young's modulus for ribs was determined with of data from both MTS and DIC and the Poisson's ratio was calculated by means of the relation between longitudinal and transverse strain.

\section{Results}

The deflection arrow for each rib was determined from DIC diagrams at maximum load. The obtained results were compared with displacement measured on MTS cross-bar (Fig. 4a). In the DIC probe it was possible to measure the maximal displacement. On the basis of these data Young's modulus values were calculated for individual ribs (Fig. 4b). The highest mean Young's modulus value obtained from MTS was 1761.3 MPa for rib no 4 and 1934.1 MPa obtained from DIC. The lowest values from MTS, 1600.8 $\mathrm{MPa}$, was observed for rib 6 and $1755.2 \mathrm{MPa}$ obtained from DIC.

The conducted tests also allows for analysis of swine body mass influence on rib bones Young's modulus value. The obtained results were divided into two weight groups, under $90 \mathrm{~kg}(75 \mathrm{~kg}-90 \mathrm{~kg}$ ) and above $90 \mathrm{~kg}(91 \mathrm{~kg}-110 \mathrm{~kg})$. The conducted analysis showed that the Young's modulus value for the fourth, fifth and sixth rib was higher in the group above $90 \mathrm{~kg}$. The ribs strength increased along with the increase of body mass. The most significant difference was noted for rib 5 where the Young's modulus increased by $252.5 \mathrm{MPa}$, whilst the smallest one was determined for rib 4 where the Young's modulus increased only by $29.3 \mathrm{MPa}$ (Fig. 4c). The highest maximum value strength was noted for rib 6: $435.8 \mathrm{~N}$, and the lowest for rib 4: $358.9 \mathrm{~N}$. Measured value of Young's modulus of the rib seems to be roughly by one order of magnitude less than expected. These differences may result from the young age of pigs and also from the specific manner of breeding (obtaining large mass in a short time).

a)

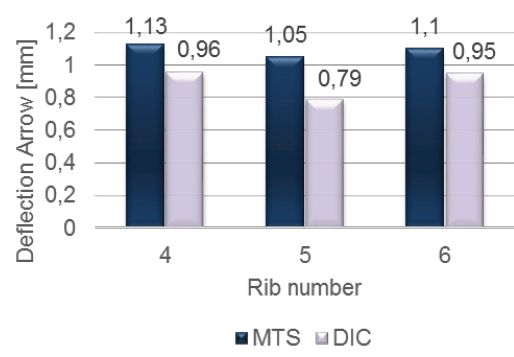

b)

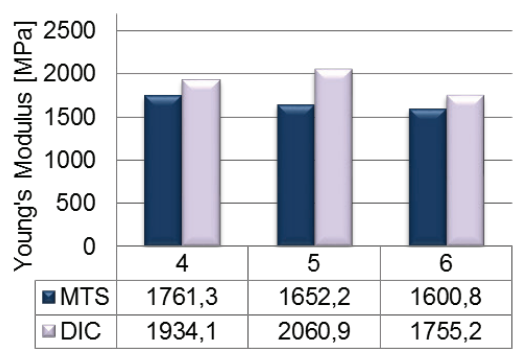

c)

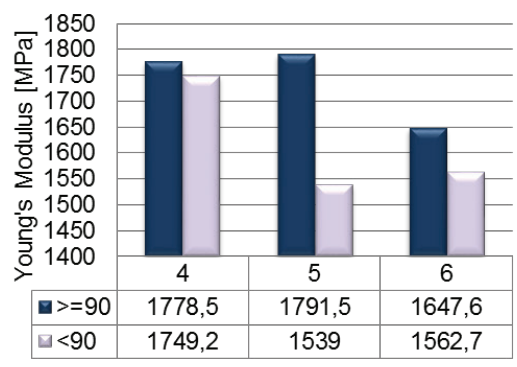

Fig. 4: Young's modulus for swine ribs: a) mean values with standard deviations obtained in two methods, b) mean values depending on body mass

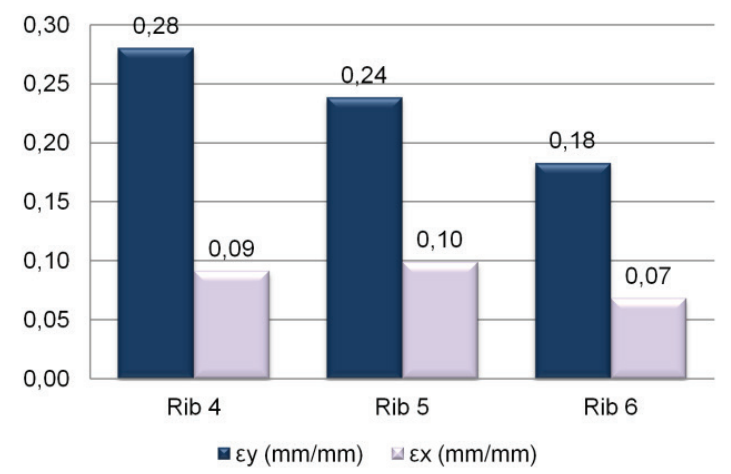

Fig. 5: Mean values of longitudinal and transverse strain obtained in DIC for swine ribs. 
a)

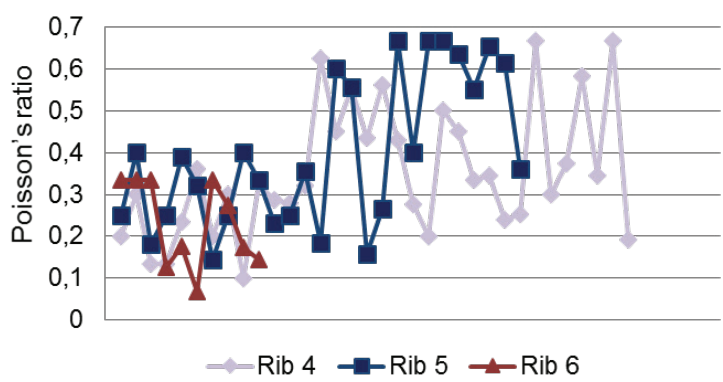

b)

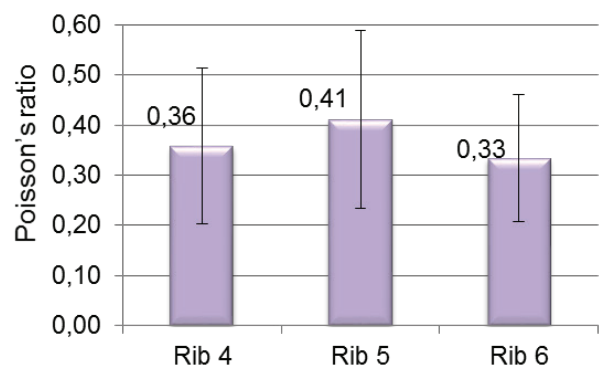

Fig. 6: Poisson's ratio for swine ribs obtained in DIC, on the basis of the longitudinal and transverse strain a) data for individual ribs, b) mean values with $S D$

The tests conducted with digital image correlation aimed to measure the strains in two directions (longitudinal $\left(\varepsilon_{x}\right)$ and transverse $\left(\varepsilon_{y}\right)$ ). Analysis of transverse strains (Fig. 6) shows, that for rib 4 and 5 the values are relatively comparable and for rib 6 there is difference of about 0.1 [mm/mm]. Obtained results enable to calculate the Poisson's ratio for each specimen (based on equation 2). Values presented in the Fig. 6b was determined for rib by means as isotropic material (without differentiation on the cortical and cancellous structures).

\section{Conclusions}

In this article it was presented a novel method of determination of bones' mechanical properties, with the use of digital image correlation during 3-point bending. Obtained results indicate that the DIC method is more accurate. Also the main advantage is that it is possible to calculate the Poisson's ratio directly from obtained experimental data.

\section{References}

Agnew A. M., Schafman M., Moorhouse K., White S. E., Kang, Y.S.: The effect of age on the structural properties of human ribs, Journal of The Mechanical Behavior of Biomedical Materials, 41, 2015, pp. 302-314.

Bradley A. L., Swain M. V., Waddell J. N., Das R., Athens J. A., Kieser J.: A comparison between rib fracture patterns in peri- and post-mortem compressive injury in a piglet model, Journal of The Mechanical Behavior of Biomedical Materials, 33, 2014, pp. 67-75.

Gzik-Zroska B., Wolański W., Gzik M., 2013, Engineering-aided treatment of chest deformities to improve the process of breathing, International Journal for Numerical Methods in Biomedical Engineering, 29, 9, pp. 926-37

Kajzer A., Kajzer W., Gzik-Zroska B., Wolański W., Janicka I., Dzielicki J., 2013, Experimental biomechanical assessment of plate stabilizers for treatment of pectus excavatum, Acta of Bioengineering and Biomechanics, 15, 3, pp. 113-21

Kemper A., McNally C., Pullins C., Freeman L., Duma S., 2007, The biomechanics of human ribs: material and structural properties from dynamic tension and bending tests, Stapp car crash journal, 51, pp. 235-73.

Kokot G., Binkowski M., John A., Gzik-Zroska B., 2012, Advanced mechanical testing methods in determining bone material, Mechanika, 18, 2, pp. 139-43

Maltese M, Castner T, Niles D, Nishisaki A, Balasubramanian S, Nysaether J, Sutton R, Nadkarni V, Arbogast K.B., 2008, Methods for determining pediatric thoracic force-deflection characteristics from cardiopulmonary resuscitation, Stapp Car Crash Journal, 52, pp. 83-105

Perz R., Toczyski J., Subit D.: Variation in the human ribs geometrical properties and mechanical response based on X-ray computed tomography images resolution, Journal of The Mechanical Behavior of Biomedical Materials, 41, 2015, pp. 292-301.

Pezowicz C., Głowacki M., 2012, The mechanical properties of human ribs in young adult, Acta of Bioengineering and Biomechanics, 2, 14, pp. 53-60

Schafman M. A., Kang Y.S., Moorhouse K., White S. E., Bolte IV J.H., Agnew A.M.: Age and sex alone are insufficient to predict human ribs structural response to dynamic A-Ploading, Journal of Biomechanics, 49, 2016, pp. 3516-3522 